\title{
TRANSDISCIPLINARY DESIGN PRACTICES IN EDUCATION: A COMPLEX SEARCH FOR INNOVATION IN NATURE
}

\author{
John McCARDLE, Ross ANGUS and James TROTT \\ Loughborough Design School, Loughborough University, UK
}

\begin{abstract}
Working across, between or even beyond established disciplines necessitates effective collaboration, and there are well acknowledged models of associating business and science. Evidence suggests a worldwide increase of cross-disciplinary working as partnerships transcend the confines of predefined and historical silos. However, associations between design, engineering and many branches of life science, lags. While there is increasing interest in bioinspired design, formalised methods are not, as yet, well established, adopted in industry or part of design curricula.

Biomimicry as a route to innovation is currently thought to rely on the collaboration between the diverse disciplines of biology, design and engineering in order to be successful. However, current academic research into multidisciplinary collaboration within engineering and product design education appears limited. This study describes the findings of a small-scale research project exploring the attitudes of professionals in relevant fields regarding interdisciplinary collaboration with a specific focus on biomimicry. The work compares current views on collaborative work in biomimicry with the opinions of an expert panel. Two rounds of questionnaires utilising the Delphi method were used to gain insights from an anonymised panel of experts. The research concluded that while biologist/designer collaboration can spark imagination and enthusiasm, it is a challenging process and its efficacy will depend upon understanding and motivation from the onset. The discussion and conclusions focus on the need for more efficient methods to encourage successful collaboration across life sciences and the impact on design education at HE and beyond. Importantly it draws attention to possible attitudes of indifference towards inter and transdisciplinary partnerships.
\end{abstract}

Keywords: Disciplinary research, design education, collaboration, life sciences, biomimetics

\section{INTRODUCTION}

In 2008 the Design Research Society held its biennial conference at Sheffield University, UK, under the banner, "Undisciplined!" in recognition of the changing landscape of design practice. The theme focussed on the inter-disciplinary and trans-disciplinary nature of future models of design. The last ten years since has witnessed the emergence of design thinking, a systems approach that has pervaded numerous and diverse sectors, crossing disciplines and giving rise to innovations in experience design and service design. The emergence of speculative design as a contemporaneous method to provoke societal issues has pushed design beyond that of the tangible, and opened new avenues in political and ethical practices, embracing ecological and sustainability values and bringing together designers and publics [1].

Working across, between or even beyond established disciplines necessitates effective collaboration, and there are well acknowledged models in associating business and science. Indeed, evidence suggests a worldwide increase in co-authorship of scientific papers that bridge disciplines as working partnerships develop out of the confines of predefined or historical silos [2]. However, the same cannot be said for design and many branches of life science.

Recent interest in biomimicry has been expedited by the enormity of existing knowledge in the biosciences and the apparent possibilities to be creatively inspired by nature. Biomimetics necessitates knowledge across the diverse sub-disciplines of life sciences and design in order to seek bio-inspired solutions and epitomises the interdisciplinary challenges that face the modern design practitioner. For 
designers to engage with biomimetics, collaboration with biologists and scientist across multiple disciplines is currently viewed as crucial.

While there is an increasing number of biomimicry special interest groups, specialist institutions, and supporting websites publicising example solutions to design problems, studies of biomimicry methodologies within design practice are relatively scarce. There is, "little scholarly research into collaboration between designers and scientists in the context of scientific research" [3].

This study aimed to explore some of the challenges to the collaboration between designers and specialist natural scientists in delivering mutually beneficial modus for innovating. Collaboration is currently evident within some projects and enterprises, however there is limited consideration of the perceived benefits for individuals in their professional fields. The work highlights the need to support a process that promotes and encourages collaboration, including experiences within design education.

\section{LITERATURE SURVEY}

Cross-disciplinary collaboration is clearly an imperative for successful design enterprises [4]. However, there is limited research considering the perceived benefits for individuals within their own professional fields outside of design, or indeed initiatives to encourage and promote regular partnering with designers. Within design disciplines there is strong evidence of designers collaborating with designers and educational approaches have been developed as part of HE curricula such as the Global Studio [5]. Nevertheless, how to best instigate and conduct inter, and transdisciplinary work is in question, and in particular how this is encouraged in a professional practitioner sense through continual professional development.

\subsection{Interdisciplinary collaboration}

Cases of successful collaboration between designers and scientists exist more commonly where there is a serviceable goal, for example on medical applications where designers are seen as facilitators to the problem solving of other professions [6]. More diversely, between synthetic biology and art \& design, the 2009 iGEM competition produced compelling results. synthetic biologists and designers collaborated to create a drug taking proposal that combined scientific viability and human usability in the form of colour theory. In reporting, Damm et al concluded that, "while natural scientists work on highly specialised questions and engineers develop new technologies closely tied to scientific knowledge and economic challenges, designers are using existing technologies to make new products. The influence of science on art and design is undeniable. However, the exchange of information between the disciplines would benefit from increased reciprocity, such that artists serve an integral role in scientific/cultural innovation." [7].

Despite such examples, and even research funding body's attempts to encourage artists and scientists to work together (e.g. The Wellcome Trust [8]), many agree that the success of linking disciplines in collaboration is so far limited. But there is gathering recognition that design is not just a unidirectional service industry but can play a transdisciplinary bidirectional part in collaborative projects. It has been argued that the inclusion of designers in scientific research can have a number of positive effects on the outcome of investigations including;

- Constructing models of representation and simulation that allow scientists to unlock their tacit or implicit knowledge. These artefacts can be collected and organised to give researchers a holistic view of their work, allowing them to reflect on their processes and unlock their own tacit knowledge.

- $\quad$ Finding ways to apply scientists' underlying theories and to prototype ideas meeting the different project stakeholders' agendas.

- Developing prototypes that permit either quick or rigorous testing of ideas.

- Challenging scientists' perceptions on their data by being exposed to designers' representations, which can become a catalyst for new research routes or ideas [6].

\subsection{Biomimicry}

Within the nascent practice of biomimicry, design innovation is inspired by nature [9]. Success within this field relies on the assimilation of biological knowledge of the natural world, with design and engineering principles [10]. For industrial designers to engage with a biomimetic process requires an understanding of natural systems, for which it is generally considered that collaboration with biologists is likely or a necessity, "Biomimicry still requires exploration, innovation and creativity, but by thinking 
like or working with a biologist we must learn to ask a different set of questions and look to nature for inspiration and learning opportunities" [11].

While collaboration has long been an important aspect of business and science, this trend in biomimetic design is in its infancy [12], and evidently there are more difficulties to overcome when collaboration is between biologists and creative designers. Researchers maintain that studies regarding the effective application of biomimicry within product design are scarce and support materials to help industrial designers get to know and approach biomimicry is lacking [13] and there is little scholarly research into collaboration between designers and scientists in the context of scientific research [3]. Therefore, in order for biomimicry to progress it is important to understand the factors hindering its uptake, starting with the motivations for professionals across fields of practice.

\section{METHODOLOGY}

An important aspect of developing methods of collaboration is considering a priori opinions of professional practitioners. Therefore, to add to the academic conversation of biomimicry, the research here focused on ascertaining the perceived efficacy of collaboration as viewed by professionals in the fields of design and biology.

This study aimed to explore, through professional opinions, whether improved collaboration between designers and scientists would have a beneficial effect on the development of technologies and products. In addition, as with new design approaches, it was important to explore the appropriateness of integrating biomimicry as a practice into an existing design syllabus and seeking student opinions on workload and enthusiasm for the method.

\subsection{The Delphi Method}

The Delphi methodology is considered an effective tool for primary research regarding decision making and forecasting [14] and is appropriate as a way in which to obtain a consensus from a group of experts [15]. It is a method that does not require physicality and can be conducted remotely, avoiding confrontation and personal bias. A Delphi panel membership can vary greatly in number, ranging from 4 to 98 [14]. The method requires, anonymity, an iteration, controlled feedback, and the statistical aggregation of group responses. As the aim of the research was to consult with professional from different fields within the umbrella of design and biology, the participants were university academics and lecturers with research and industrial experience within their respective disciplines.

This study consisted of 6 experts from a pool of 14, three biologists and three designers, all current academics involved with research, teaching and enterprise activities. Within these umbrella disciplines the fields represented were: Biomechanics, Biochemistry, Design Practice Research, Sustainable Design and Design for Digital Fabrication.

Anonymity and iteration were achieved with two rounds of questionnaires. The initial 5-point Likert style questionnaire was designed to ascertain current attitudes regarding the worth and practicality of collaborative working. The second round showed the consensus from the first round and invited the members to attempt explanations for the cases. In all, the questions were designed to elicit opinions, and although personal experiences were expected, members were aware that they were representing their profession and to be as objective as possible. Abridged questions from the two rounds are given in Table 1.

\section{RESULTS \& DISCUSSION}

The results of Table 1 showed a consensus to Round 1 Question 1 (R1Qu1), implying that collaboration is encouraged. However, within the panel, the biologists strongly agreed, and designers formed remained neutral towards the statement.

This split was again seen in R1Qu2 where the consensus showed the panel balanced between agreement and neutrality. However, within this result the biologists all agreed with the statement, with the designers remaining neutral.

In response to R1Qu3, there was strong neutrality with some disagreement about the specifics of designer/biologist collaboration benefits. Although this was specifically in terms of biomimicry the responses prompted the follow-up R2Qu2 to probe further.

$\mathrm{R} 1 \mathrm{Qu} 4$ generated more positive agreement with relatively few comments being neutral. Most responses agreed that collaborating across disciplines would likely improve scope of knowledge. 
Other noteworthy results, which informed the second round of questions, were found within R1Qu5 wherein the panel felt current or recent projects with their involvement, or awareness of, would not benefit from inclusion of expert advice from an outside field.

Table 1. Abridged Delphi Method Results

\begin{tabular}{|c|c|c|c|}
\hline Qu & Round 1 & Consensus & Selected Comments \\
\hline 1 & $\begin{array}{l}\text { Active collaboration in my field is } \\
\text { encouraged }\end{array}$ & Agree & \\
\hline 2 & $\begin{array}{l}\text { Issues prevent cross disciplinary } \\
\text { collaboration }\end{array}$ & Agree/Neutral & \\
\hline 3 & $\begin{array}{l}\text { Des/Bio collaboration would benefit my } \\
\text { field }\end{array}$ & Neutral/Disagree & \\
\hline 4 & $\begin{array}{l}\text { Des/Bio collaboration would widen my } \\
\text { knowledge }\end{array}$ & Agree/Neutral & \\
\hline 5 & $\begin{array}{l}\text { Past projects should have had input from } \\
\text { another field }\end{array}$ & Disagree/Agree & \\
\hline 6 & $\begin{array}{l}\text { There is effective knowledge sharing in my } \\
\text { field }\end{array}$ & Agree/Neutral & \\
\hline 7 & $\begin{array}{l}\text { Who would benefit most, Biologists or } \\
\text { Designers? }\end{array}$ & Equal & \\
\hline Qu & Round 2 & & \\
\hline 1 & What is the greatest collaborative issue & & $\begin{array}{l}\text { Speed of process } \\
\text { Legal requirements } \\
\text { Making connections } \\
\text { Competing priorities }\end{array}$ \\
\hline 2 & $\begin{array}{l}\text { My current project would not benefit } \\
\text { because... }\end{array}$ & & $\begin{array}{l}\text { Unrelated to another } \\
\text { discipline } \\
\text { Too far along in the } \\
\text { process } \\
\text { Need to be included in a } \\
\text { proposal } \\
\text { Too complicated }\end{array}$ \\
\hline 3 & Preferred method of knowledge sharing & & $\begin{array}{l}\text { Face-to-face } \\
\text { Conference } \\
\text { Journal } \\
\text { Social media }\end{array}$ \\
\hline $\begin{array}{l}4 \\
5\end{array}$ & $\begin{array}{l}\text { Preferential view on support tools } \\
\text { Is biomimicry an attractive proposition }\end{array}$ & $\begin{array}{l}\text { Strongly Agree } \\
\text { Neutral/Agree }\end{array}$ & Preference for workshop \\
\hline
\end{tabular}

The second round of questions, derived and informed from Round 1, provided some clarification of the issues perceived by the panel. The open questions delivered some insightful feedback on issues currently hindering collaboration, including; 'red tape' - the legal agreements necessary to allow collaboration between institutions; "It is difficult to access the right people or information that relate to the problem"; "Competing priorities, others tend to have other important things to do"; "Having the existing connections; finding suitable connections; and the extra complexity associated with it." And, "it slows down the process". Such responses could be considered as relating to organisational and communication problems. The legality of projects, such as intellectual property rights is pertinent and while NDAs and IPR are mainstream ethical considerations, these are clearly viewed as serious hurdles to collaborative research.

The second follow up question, R2Qu2, considered the perceived lack of benefit within the inclusion of a current or recent project. The question aimed at allowing panellists to consider the benefits of collaboration, and potentially reflect on the suitability of ongoing projects that would benefit from outside expertise. The consensus showed the majority remained neutral or in disagreement. There was 
a consideration that, "In most research projects collaborations need to be set up in the initial stages when the proposal is being written." This is perhaps reflected in the nature of academic funding and the possible inflexibility of changing paths within a running project and allocated budget. There also appeared to be a fixed view to opening research foci to other disciplines and an avoidance of working outside the norms of a research silo.

As a point of discussion was the panellist's response to the potential personal benefits of collaboration and that of knowledge sharing. Responses to R2Qu3 showed somewhat a biased view of the topic. The immediate reaction was in sharing knowledge outwardly rather than inwardly or bi-directionally. Although the methods listed were not in themselves surprising, and indeed support bi-directional knowledge, the emphasis seems to have been on the promotion of research and knowledge rather than the collaborative sharing of knowledge for a common goal.

R2Qu4 aimed to discuss insights into the use of existing tools and processes that have been proposed and available via internet sites (e.g., AskNature.org (https://asknature.org/). While web-based tools are on the increase, including innovation databases for past projects, materials etc. and digital collaborative working support tools in product lifecycle management. The question centred on whether the panel considered online databases as a viable preference to interaction with professionals. The unanimous consensus of the panel confirmed that interaction with professionals (as workshop practice) was preferred, despite the specific development of such tools to support collaboration in design.

Finally, considerations for the engagement of biomimicry as a collaborative exercise was explored. The general feeling was one of overwhelming neutrality. The concept of biomimicry as a formal innovation method is in its infancy and although there is increasing evidence of successes, it seems to be viewed with a degree of scepticism. It's clear that emerging technologies are disruptive and there is a reluctance to be an early adopter when the perception that existing methods of innovation and known collaborations presents less risk and, in some cases, a better chance of attracting funding.

\subsection{Considerations for Design Education}

This work has considered the efficacy of collaboration between designers and biologists and the motivation for professionals to widen their scope. One of the objectives of the study was to assemble a diverse panel of professionals from various fields to represent a wide interest group rather than divided into the separate views of biologists and designers. The subject of education in design and/or biology was not discussed directly but the results bring into focus possible attitudes of leading professionals and the challenges that may exist in fostering better informed approaches to collaborative working.

The need to address these challenges presents opportunities at both university level and in continual professional development through supporting professional institutions. From a biology perspective, the key skills of designers in analytical design thinking and the constructing of models, simulations and prototypes could be embraced as a method to challenge biological concepts. From a design perspective, discussing and challenging biological concepts, and accepting the role of a biology collaborator, much like the work of a biologist at the Design Table [16], would be an interesting educational experience.

\subsection{Recommendations for further work}

The aim of this small and limited study was conducted to explore the potential of open dialogue between disciplines at a local level. It is worth noting that the data highlights some interesting areas for discussion in terms of varying incentives or motivations between fields, which could be explored further. Of course, the scale of the study needs to be increased to gather more quantitative results to justify further action, but even with the narrow snapshot here, evidence suggests the need to encourage an open mind in collaborative thinking. The co-operation between the fields of biology and design needs to be mutually beneficial. Indeed, the over-riding consensus of this study was that this relationship should benefit both fields equally. Nevertheless, the facilitation and dissemination of practice-based methods in biomimicry continues to be a challenge.

\section{CONCLUSIONS}

Current thinking suggests that biomimicry and collaboration are inseparable and mutually beneficial. However, with insights from experts it is apparent that the process is more complex than simply sharing of knowledge and ideas, despite the tools currently being developed.

The primary recommendation centres on improved communication and dissemination. The insights from the panels across the two rounds of the Delphi method highlighted that interdisciplinary interaction 
with professionals was preferable to independent and more remote sources of information. However, finding and setting up a collaboration was not considered straight forward. Issues such as appropriate professional credentials, legalities of intellectual property protection and timeliness all presented challenges.

Within the variety of work undertaken by both disciplines and sub-disciplines, the success of the collaboration is likely to rest on moulding it to the specific requirements of a project. The notion of designer/biologist collaboration appears to be accepted a good one; however, the efficacy and benefits will ultimately depend on the individual case. It could be argued that the strength of biomimicry in moving forward is within its diversity of approach, but consequently viewed as resource intensive and costly as each project is adjusted to a different or varied approach rather than a formulaic one. Such individuality in approach should be a consideration for educators, as design innovation practices are inevitably dynamic and competitive.

\section{REFERENCES}

[1] Gatto G. and McCardle J. The designer and the scientist : The road to inspire transdisciplinary synergies. In: International Conference On Engineering And Product Design Education. Aalborg, DK: Design Society \& IED; 2016.

[2] Sonnenwald D.H. Scientific collaboration. Annu Rev Inf Sci Technol. 2007.

[3] Peralta C. and Moultrie J. Collaboration between designers and scientists in the context of scientific research : A literature review. In: Design Information and Knowledge. 2010.

[4] Cummings J.N. and Kiesler S. Collaborative research across disciplinary and organisational boundaries. Social Studies of Science. 2005.

[5] Ghassan A. and Bohemia E. The Global Studio. FORMakademisk. 2015.

[6] Peralta C. and Moultrie J. Collaboration between Designers and Scientists in the Context of Scientific Research. In: DS 60: Proceedings of DESIGN 2010, the 11th International Design Conference. 2010.

[7] Damm U., Hopfengärtner B., Niopek D. and Bayer P. Are artists and engineers inventing the culture of tomorrow? Futures. 2013;48:55-64.

[8] Jeffries S. When two tribes meet: collaborations between artists and scientists. The Guardian [Internet]. 2011 Sep 21; Available from: https://www.theguardian.com/artanddesign/2011/aug/21/collaborations-between-artists-andscientists.

[9] Benyus J.M. Biomimicry: Innovation Inspired by Nature. Innovation. Harper Perrenial; 1997.

[10] Vincent J.F.V. and Mann D.L. Systematic technology transfer from biology to engineering. Philos Trans R Soc A Math Phys Eng Sci. 2002;360(1791):159-73.

[11] Charter M. and Clark T. Product sustainability: organisational considerations. Int J Prod Dev. 2008.

[12] De Pauw I.C., Karana E., Kandachar P. and Poppelaars F. Comparing Biomimicry and Cradle to Cradle with Ecodesign: A case study of student design projects. J Clean Prod [Internet]. 2014;78:174-83. Available from: http://dx.doi.org/10.1016/j.jclepro.2014.04.077.

[13] Volstad N.L. and Boks C. Biomimicry - a useful tool for the industrial designer? Nord 2008 [Internet]. 2008; Available from: https://www.designsociety.org/publication/27376/biomimicry__a_useful_tool_for_the_industrial_designer.

[14] Rowe G. and Wright G. The Delphi technique as a forecasting tool: Issues and analysis. Int J Forecast. 1999;15(4):353-75.

[15] Dalkey N. and Helmer O. An Experimental Application of the DELPHI Method to the Use of Experts. Manage Sci. 2008.

[16] Peters T. Nature as measure: The Biomimicry Guild. Archit Des. 2011;81(6):44-7. 